\title{
Beyond the Meeting: How Community Activists Construe Idea Transfer from Intercommunity Encounters - The Cases of Northern Ireland and Kosovo
}

\author{
Katharina Ploss* \\ Department of Political Science, Bilkent University, 06800 Ankara, Turkey \\ (E-Mail: ploss@bilkent.edu.tr)
}

Received 17 May 2010; accepted 5 September 2010

\begin{abstract}
Intercommunity dialogue encounters are a crucial tool for constructive conflict resolution. This research examines grassroots dialogue encounters with regard to the societal position of the participants, as well the situation 'on the ground' as influential to the transfer process. Interviews in Northern Ireland and Kosovo with community activists stressed the effectiveness of personal characteristics of dialogue participants when it came to transfer. Moreover, the readiness - affected by socio-economic conditions as well as external/secondary conflict parties - of the peer group to listen to its participant seemed fundamental.
\end{abstract}

\section{Keywords}

transfer, intercommunity dialogue, social influence, personal credibility of community activists, socioeconomic conditions, Northern Ireland, Kosovo

When a society has suffered a protracted conflict, adverse parties do not easily reunite. Under the continued rule of violence, lives change tremendously and horrible crimes are committed. The question of how to extract a society from a severe and intractable conflict is addressed by post-conflict peacebuilding efforts, and is not an easy task. Immense obstacles face those who have suffered in the conflict and those who reach out beyond the front lines to try to establish a better relationship with the former enemy. One critical component of the complex peacebuilding process is dialogue or similar meetings between conflicting parties. These meetings take place on all societal levels, engaging political decision makers, as well as participants in civil society initiatives at the grassroots level.

*) Katharina Ploss is a post-doc at the Department of Political Science at Bilkent University in Ankara. She has substantial practical experience with intercommunity dialogue in various locations across the globe, as well as online. 
Ideally, the setting of a dialogue meeting allows participants to develop new ideas to address their conflict and find mutually acceptable areas of agreement. At the same time, the participants work on the improvement of their interpersonal, and thereby intergroup, relationships (Mitchell 1993: 79). Dialogue meetings can therefore offer a unique chance to address the deeds of the past and work together towards a joint future. Organizers, facilitators and participants usually pursue two aims, of which the latter group may be less overtly aware. First, the attitudes and perceptions among participants of the dialogue encounters should change. This means that positive change is expected to take place on the microlevel, largely through interpersonal connections within the small group. Second, these positive changes should be transferred out of the dialogue meeting venue and into the constituencies and peer groups of the participants (Kaufman 2002; Mitchell 1981; Rouhana 2002). If the new insights are successfully passed to the peer groups, this may induce a change in attitudes on the macro-level of the community and subsequently in society, multiplying the scale of any positive outcome and contributing to the overall peacebuilding process in the conflict area. Although the concept of "involve a few, reach many" is undoubtedly appealing, transfer of new insights from dialogue meetings to a wider audience is an underresearched topic in the field of conflict resolution - even though the challenges of transfer processes are very prominent. Fisher (2005), one of the first and few to develop a model of transfer effects, suggests how information gained during Interactive Conflict Resolution meetings can trickle to political decision makers and public opinion. ${ }^{1}$ Studies of top-level conflict resolution encounters have also allowed crucial observations to be made: Chataway (2002), Fisher (1997, 2005), Kelman (1997, 1998, 2000), Rouhana (2000) and others pointed towards two factors that seem to affect the transfer process: 1) the position of the participant of the dialogue encounter among his constituencies and 2) the degree of tension 'on the ground' which may prevent the participant from sharing any positive perception or information about the other conflict party with his peer group as the participant fears being punished for that.

The how and why of the transfer process remains vague despite the prominence of cases like Kelman and Rouhana's interactive problem solving workshops addressing the Israeli-Palestinian conflict, especially during the phase prior to the Oslo agreement of 1993, in which the participants were able to transfer ideas from the workshop series upwards to the political decision-making level (Kelman, $1998,2000,2005) .{ }^{2}$ Transfer processes are even more opaque when it comes to

\footnotetext{
1) Fisher (2009) provides a comprehensive overview of the vast amount of dialogue meetings conducted in conflict resolution practice. He stresses numerous descriptions of these meetings between former adversaries and labels referring to these encounters. The names differ slightly but tend to refer to the same thing, such as Burton's controlled communication, Montville's track-two diplomacy, Azar's problem-solving forum, or Chasin and Herzig's facilitated dialogue.

2) Transfer of changes is expected to happen upwards to political decision makers (Kelman, 1972), down-
} 
grassroots initiatives. Conflict resolution scholars like Fisher and colleagues have predominantly concentrated on meetings between elites or medium-level political actors such as religious leaders. Hardly any attention has been paid to transfer processes from grassroots community activists to their peer groups, and little is known about how the community activists conceptualize the process of passing on information and insights. The primary goal of this article is to expand the knowledge of the transfer process to address gaps with regard to grassroots community activities.

When it comes to information transfer, it seems worthwhile to look beyond the relevant conflict resolution literature to a larger theoretical umbrella: social influence. This allows the research question to be posed in social-psychological terms. What do community activists in Northern Ireland and Kosovo believe allow them to influence the opinions of their peers groups? What are the aspects that they consider significant for the transfer, i.e. the influence process? What may inhibit the activist's impact on his peers? Apparently, information transfer from intercommunity dialogue can easily be seen as a process of social influence.

The studies on social influence suggest various models how social influence takes place and what might prevent it. Martin and Hewstone (2003:312) argue that social influence "refers to the ways in which the opinions and attitudes of one person affect the opinions and attitudes of another person." For understanding the motives and concerns of the community activists, studies on minority influence on majority groups are particularly interesting (e.g. Moscovici, Lage and Naffrechoux, 1969; Moscovici and Personnaz, 1980): community activists and their presumably positive attitude towards the other conflict party, the outgroup, tends to be the minority opinion. The peer groups of the community activists, however, are inclined to hold an antagonistic opinion about the other conflict party. This hostile opinion is, on average, widely held in society and consequently qualifies for the majority attitude. Therefore, this study analyzes how a minority perceives its influence on a majority opinion.

Kelman has been influential in developing concepts of social influence and applying them beyond the academic laboratory setting to real life conflicts. $\mathrm{He}$ distinguishes between three processes of social influence (1958): compliance, identification, and internalization. When a person complies, he accepts being influenced by another person because he expects to benefit from that or because he is afraid that he would be punished if the influence is not accepted. Hence, the person influenced changes his opinion to receive a reward or avoid punishment, rather than because he believes in the message. Identification means that a person accepts the influence of another person because he wants to build up or preserve a "satisfying, self-defining relationship to another person or a group"

wards to grassroots (Kaufman, 2002), or laterally between dialogue participants of different initiatives (Cuhadar, 2009). 
(Kelman 1958:53). The last process of social influence proposed by Kelman is internalization. Here, a person accepts being influenced because the message that is transferred to him is in line with his personal value system. French and Raven (1968) picked up on Kelman's distinction and elaborated on it. They suggest reward power (resembling Kelman's compliance) and referent power (identification, in Kelman's terms). French and Raven further differentiate between coercive, legitimate, and expert power. Coercive power is similar to reward power but upside down: a person accepts the influence of another person because he is afraid of punishment if he fails to adhere to that influence. A person influences another person through legitimate power when that other person accepts influence because he feels obliged to do so. Expert power is exerted when a person agrees to being influenced because he considers another person as having expert knowledge on a particular topic. This special knowledge gives that other person expert power.

Then, according to social influence literature, what makes people listen to information transferred to them? Apparently, it matters significantly how people perceive the source, i.e. the person, of information and what standing or reputation that person is ascribed to by others (Cartwright and Zander 1968; Cialdini 1984; Klapper 1960). Cartwright and Zander argue that a person who is very prestigious tends to be very credible for his peer group. Hence, his prestige allows him to influence others. What is more, the authors outline that members of well established groups exert a special influence on each other. Group members may try to model their behavior according to the behavior of a leader, hero, or any other person who has suffered for the group. Therefore, the leader or hero is able to affect other members of his peer group because these members are positive about this influence. The ideas and findings about the identification of the influencee' with the 'influencer' put forward by Cartwright and Zander, French and Raven, as well as Kelman, seem to relate fairly well to Mugny and Perez (1991) and Turner's (1991) suggestions on minority influence. Mugny and Perez claim that minorities affect others, when these others perceive identifying with that minority as congruent with a positive social identity. In Mugny and Perez' take, minorities impact on others when the minorities are categorized as ingroup. This observation is in close line with self-categorization theory in which people identify with a particular group and conform to a prototypical group position (Turner 1991). Turner, Wetherell, and Hogg (1989) described this type of social influence as referent informational influence.

Moscovici et al. (1969) explain minority influence on majorities slightly differently. Here, the most cited factor for minority influence is consistency. Moscovici et al. argued that minorities need to act consistently over time in order to affect majorities, i.e. minorities would need to repeat the same answer or information again and again if they wanted to impact on the majority opinion. Nemeth, Swedlund, and Kanki (1974) extended this finding. They claimed that for a minority to successfully influence the majority, it should not necessarily only 
repeat the minority position persistently but rather be very confident about their minority opinion. This way, majorities tend to focus on the minority point of view. Majorities might re-check their opinion and use the minority attitude as a stable focal point to which they can move. What is more, minorities should ideally be part of the ingroup and be credible to other ingroup members (Clark and Maass 1988). Especially, source credibility seems to be important as Clark and Maass found that source credibility of the ingroup minority is linked with an intrinsic, private change of attitudes in contrast to an extrinsic, public one. Hence, people accept influence because they respect or admire the influencer, or find the influencer trustworthy and credible, or concur with his values. Besides, people are motivated to process information when they perceive the information as highly personally relevant (Petty, Cacioppo and Goldman 1981). People listen to information and accept influence because they do not want to deviate from ingroup norms or because they want to have detailed knowledge about a particular topic (Deutsch and Gerard 1955) and have a solid need for cognition (Cacioppo and Petty 1982).

In-depth interviews were conducted with community activists in Northern Ireland and Kosovo to shed light on the process of grassroots peacebuilding. The term "community activists" was chosen because the interviewees have been active within and across the community divide. The activity includes the facilitation of, and participation in, community dialogue groups or other related initiatives that focus on intercommunity relations, interface work in the case of Northern Ireland, working for an organization that addresses intercommunity relations, as well as mediation and mediation training work. ${ }^{3}$ Hence, the interviewees of this study have been in touch with the other community through a wide range of activities but the contact must not have necessarily taken place in the form of a formal dialogue group. The term community activist denotes that the person in question is actively engaged in intra- and intercommunity work.

As a secondary outcome of the data gathered during the course of this research, insights obtained may be useful for practitioners, especially since the study analyzed actual cases in the field. Increased understanding of community-based exchange of ideas can add significantly to the literature on transfer from dialogue encounters, and might be of significant help for practitioners in the design of their interventions. Increased knowledge about what makes a successful transfer process can allow facilitators to set up their initiatives accordingly, and may help to improve future encounters between communities in conflict.

\footnotetext{
3) Interfaces refer to areas in Northern Ireland where Catholic and Protestant areas or estates neighbor each other directly. Interface areas tend to be flashpoints at which violent clashes between the communities still occur fairly frequently. Walls and fences demarcate the borders between the Catholic and Protestant areas. Infamous examples of interface areas are the Alliance Avenue in North Belfast or the Fountain in Derry (Heatley, 2004).
} 
The lack of information on transfer from community activists' perspectives is unfortunate because the grassroots constitute the most numerous societal level. In addition, grassroots initiatives as part of an emerging civil society sector can play an important role during post-conflict peacebuilding (Belloni 2001; Peck 1998; Pouligny 2005). The minds and hearts of the people on the grassroots level, however, cannot be won over by law or by political decree. Peacebuilding processes tend to be more effective if initiatives and ideas are not only introduced from the top-down, i.e. from policy makers to grassroots (Lederach 1997), but also involve a change in attitudes coming from the people themselves. This is what makes cross-community encounters so valuable and this is why learning more about the transfer strategies of community activists is so crucial: if changes that occurred during the encounters are passed on to the entire peer groups of the participants, members of the peer groups may change their attitude as a result of what they have learned. Bottom-up approaches therefore can add significantly to top-down methods and policies which aim at sustainable peacebuilding.

If people on the community level change their attitude towards the other conflicting party this can: 1) help policy makers to implement already intended conciliatory gestures or 2) can press policy makers to consider making conciliatory gestures. In addition, policy makers themselves may be pressured to alter their opinions if they do not want to lose their constituencies. Admittedly, dialogue meetings are just one tool among many others that may trigger this transformation in attitudes, and the meetings can only initiate this alteration among a broader audience if the positive changes which occurred during the dialogue meeting are actually passed on to the peer groups of the participants. If the new insights remain with the small group of the encounter, the multiplier effect will not be realized. Hence, it is of utmost importance to gain comprehensive insights into how people who engage in cross-community encounters on the grassroots level understand the transfer process. According to Lederach (1997), people on the grassroots level face the most fundamental challenges during the post-conflict peacebuilding phase. These include issues of security, shelter, and other basic needs and for them it might be most challenging to leave behind the deeds of the past and look towards a better future in which they might live in mutual acceptance with a group of people who had previously done harm to them. Consequently, it seems most appealing to understand how transfer processes work on the grassroots level. People who engage in cross-community encounters are expected to face particularly demanding challenges, as their peer groups have suffered enormously in the conflict. These community activists might then approach the transfer process differently than has been observed for transfer processes at the top-level.

This article shows that community activists consider two aspects center stage for the transfer process to their peer groups: first, their personal credibility among their peers and second, the readiness of the peers to listen to messages coming 
from their activists. Both factors are highly interdependent: if the community activist is perceived as credible by his peers, it is easier for him to reach out to them and pass information on. However, the peer group needs to be ready for that process. If the peer group is not ready for a variety of reasons explained in detail throughout the article, it tends to be very challenging for the activist to be heard by them. The results of the study relate well to prominent findings on social influence processes outlined above: peer groups seem to accept the influence of a community activist if they perceive the activist as credible. Furthermore, the peer group needs to be motivated to process information transferred to them and thereby allow the influence to happen. Hence, the information transfer from community activists to their peer groups is clearly a process of social influence. It needs to be stressed that this study does not aim at examining to what extent the messages of the community activists were absorbed by their peers. Even though this might limit the scope of this study on the one hand, it makes the findings and conclusions presented here more robust, on the other hand. To assess the extent to which the messages were recognized by the peers, it seems advisable to investigate the opinions of the peer groups. However, this type of inquiry would need a different set-up and potentially a significant budget in order to be thoroughly conducted.

\section{Rationale and Conduct of the Research}

This article was intended to investigate how people who engage in intercommunity encounters construe the transfer of changes and messages from the initiatives to their peer groups. Even though social influence literature might suggest factors beyond the ones mentioned by the interviewees - nothing was said about a need for cognition, for example - it was the rationale of the study to present the viewpoint of the interviewees. It was anticipated that this way the reality on the ground in the communities in Northern Ireland and Kosovo would be most adequately and correctly reflected. The second aim of this project was to offer insights that would be relevant to policy practitioners. Lepgold and Ninic (2001:35) state: "knowledge is policy-relevant if it addresses the instruments, context, and/or consequences of policy."

In-depth interviews were conducted in Northern Ireland and Kosovo with people who engage in cross-community work. It was anticipated that the cases of Northern Ireland and Kosovo would offer in depth knowledge about the "appearance" of the transfer process. Northern Ireland and Kosovo are in a post-conflict peacebuilding phase and, in both cases, the interviews focused on people who engage in various ways in cross-community encounters and/or relationship development. The Good Friday Agreement in Northern Ireland was signed in 1998, while the United Nations Mission in Kosovo (UNMIK) was established in 1999, 
with a new outbreak of short-term violence in March 2004. Kosovo declared independence in February 2008. Both cases are located in Europe, with Northern Ireland in the North-West and Kosovo in South-East of the continent. The differing locations potentially would offer some culturally specific aspects to the understanding of the transfer process.

One of the major differences between the two cases has been the role of international actors on the top political level. Northern Ireland has attracted enormous international attention among politicians and scholars. Despite this interest, Northern Ireland was always predominantly perceived as problem internal to the UK, in which the international community would not interfere (De Chastelain 2003; Stevenson 1996). In addition, it seemed unlikely that the conflict in Northern Ireland would seriously threaten the security of the rest of Europe (Cox 1998). Moreover, Northern Ireland has been part of one of the most powerful and highly industrialized countries in the world, making it unlikely that the US or any country of the European Union would try to influence the government in London to address the conflict in her Northern province (Dixon 2002). Recommendations or lobbying appear probable, but anything beyond words is doubtful. When the British government allowed the US envoy George Mitchell to engage Northern Ireland in the early 1990s, he was not there to make decisions or to give directions on how to tackle the conflict between Catholics and Protestants (Curran and Sebenius 2003; Curran, Sebenius and Watkins 2004). International political actors intervened in Northern Ireland with different means and to different extents than in Kosovo. It was unlikely to expect any large scale violence of British security forces against Catholics in Northern Ireland, as was the case of Milosevic and his actions against Kosovar Albanians in Kosovo given that Peter Brooke, the British Secretary of State for Northern Ireland claimed in 1990 that Britain had "no selfish strategic or economic interest in Northern Ireland" (Brooke cited in Dixon 2002).

Elsewhere Dixon (2001) has argued that the Sunningdale Agreement of 1973 showed that the Britain had understood fairly early that there was no military solution to the conflict in Northern Ireland. Therefore, the urgency for the international community to intervene in Northern Ireland was not the same as in Kosovo. In Kosovo, international political actors have resumed a prominent role (Kuperman 2008). After NATO air strikes, the international community established UNMIK as an interim administration of the region. In contrast to Northern Ireland, local actors played less prominent roles than international actors, such as the European Union, the US, Serbia, Russia, the NATO or the UN. The international community was far more involved on the political scene, becoming an active actor on the local level rather than simply a third party trying to get the warring parties to the negotiation table (Yannis 2001). When it comes to political decision-making, therefore, the international community has 
formed a much closer relationship with Kosovo than with Northern Ireland, the integrity of which within the United Kingdom was never challenged on the international level.

The international community might have been involved differently in political decision-making processes in the two cases, but international donor agencies and NGOs have been equivalently very active in Northern Ireland and Kosovo. The community sector in Northern Ireland received considerable funding from the late 1980s onwards, with the International Fund for Ireland, started in the mid 1990s, garnering donations from the US, Australia, New Zealand and other areas as well as the PEACE programs of the European Union. More specialized NGOs, and the increasing number of women's organizations, pointed towards further expansion of the community sector (Birrell and Williamson 2001). In Kosovo, many prominent international organizations, like CARE International, UNDP, OSCE, Partners for Democratic Change, and other smaller international NGOs, began to engage in intercommunity relationship development work in a variety of capacities. The interviews, as well as field stays, revealed that the people on the grassroots level had experienced numerous attempts to post-conflict peacebuilding in their areas.

\section{Interview Partners Northern Ireland}

In total, 17 people from Northern Ireland participated in this study ( 9 from the Catholic and 8 from the Protestant community/ 7 female and 10 male interviewees). The interviewees had been engaged in intra- and intercommunity work in Northern Ireland for decades. The type of engagement varied from altruistic support of the community, through campaigning for and establishing integrated schools, to violent actions in paramilitary organizations. Today, the interviewees work in various branches of the community sector: publicly funded community organizations, community centers, as volunteer community activists, free-lance dialogue practitioners, scholars, or as political advisors. Generally, it should be highlighted that all interview partners in this study are currently engaged in a number of types of activities and different encounters within and across their communities. It is often difficult to track down the exact initiative or activity in which the interviewees have participated that is the major source of positive messages being transferred back to the peer groups. It therefore seems more reasonable, and better supported by the available data - particularly for this article - to assume that the interviewees have been influenced through a number of their associated activities. The interview partners were not just involved in a single project, but rather joined different initiatives or engaged with the other community members in a non-structured and private way. Moreover, all interviewees share a basic willingness to engage with the opposing community. 


\section{Interview Partners Kosovo}

In the Kosovo case study, two different groups of interviewees participated. In total, it was possible to speak with 18 people in in-depth interviews (15 from the Albanian and 3 from the Serbian community/ 4 female and 14 male interviewees) ${ }^{4}$ The first group consisted of interviewees from the municipality of R., who were former participants in a dialogue/workshop series that was conducted by a small international NGO from December 2005 until April 2008. Most of these interview partners had been involved in the municipal government and administration of R. In addition to their official functions in the municipality, some of the interviewees engage in farming and wine growing, both of which are typical for that rural area of Kosovo. One of the interviewees was a Serbian policeman, based in one of the Serbian enclaves in R. Another interviewee worked for a NGO focused on addressing the needs of the handicapped. A third interviewee was the local imam. The interview partners had been invited to participate in the workshop series, together with fellow members of the municipal administration/government. Most of the interview partners in this group have tried to keep in close contact with their fellow participants of the workshop series. Due to their work for the municipality, most of them continue to see each other on a regular basis.

The second group consisted of interviewees who have been engaged in - broadly stated - intercommunity development activities. One interviewee works for a nongovernmental organization that provides a variety of services, ranging from mediation to conflict resolution training, as well as gender- and ethnicity-equality awareness initiatives. Two other interviewees have been involved with two different organizations that focus on women in conflict zones, and in particular on women's empowerment and equality. A fourth interviewee works for a large international organization in Kosovo. This interviewee was involved in a special activity by that organization that concentrated on civil society development and intercommunity dialogue in Kosovo.

\section{Perceptions and Understanding of Community Activists}

The aim of this article is to answer the question of what causes idea transfer to a wider community from a community activist's perspective. The analysis of the data revealed two key aspects. From an intercommunity activist perspective, the transfer process is determined by: 1) credibility of the activist and 2) readiness of

\footnotetext{
4) The proportion of each ethnicity reflected the overall distribution of ethnic groups in the population of Kosovo to some extent: in 2006 the Statistical Office of Kosovo issued that $92 \%$ of the population were Albanian, $5.3 \%$ Serbian, $1.1 \%$ Roma, $0.4 \%$ Turkish, and $1.2 \%$ members of other ethnic groups, with a total of 2.1 million inhabitants in Kosovo (Lantschner 2008: 453; Statistical Office of Kosovo 2008: 11). Unfortunately, no Roma representative was available for an interview.
} 
his peer group to listen to the messages that are intended to be passed on to that group.

It also became apparent, however, that the meaning and implications of the factors differ on certain dimensions across the two cases. For example, the data disclosed different perspectives on what evokes credibility: it can be engagement in a paramilitary organization, which proved to the group the willingness to pay the ultimate price for the cause of the community (as argued in Northern Ireland), or it can be induced through a clean personal record of no engagement in a combat group (as claimed in Kosovo). This observation stresses the manifold way that credibility takes hold. This exploratory research project offers an initial consideration on the process of transfer on the grassroots level, which had not yet been developed. Fig. 1 provides a schematic overview.

The model of transfer, as depicted in Fig. 1, postulates that transfer is more likely to happen if the community activist enjoys high credibility among his peers. High credibility ensures that his peer group listens to him because the activist seems sufficiently trustworthy. Credibility arises from numerous factors: personal suffering, a personal history of dedication to the community, as well as a position of authority. Transfer, however, does not depend solely on the credibility of the activist. Rather, the peer group needs to be ready to listen to their activist. The

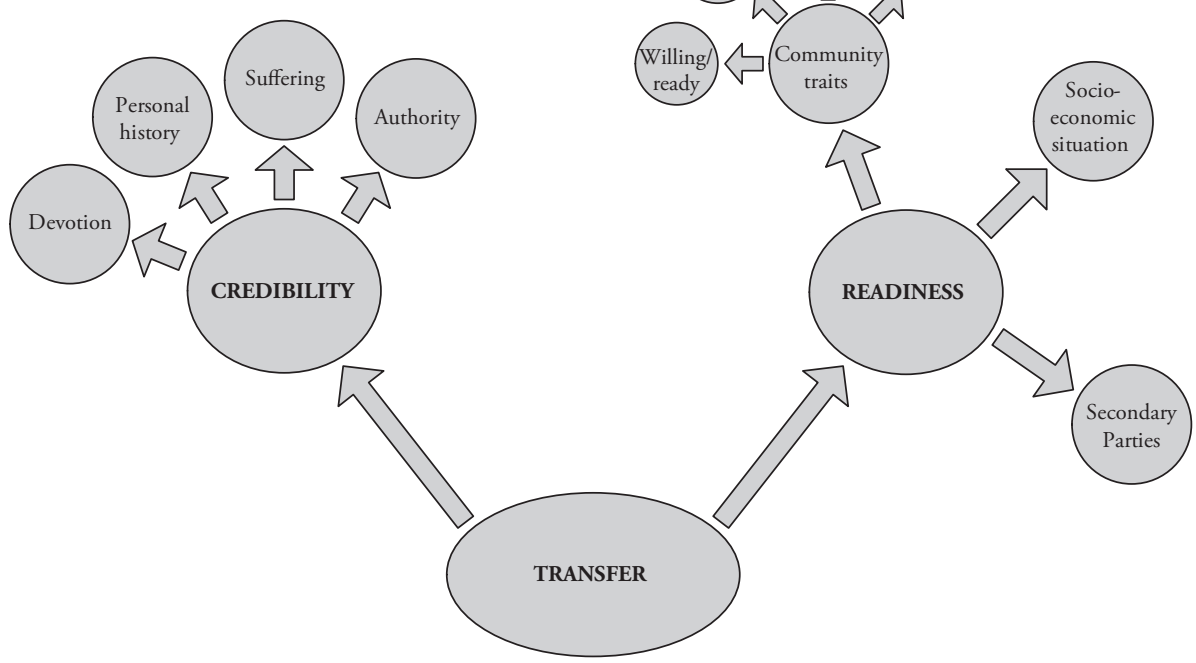

Fig. 1. A social influence model of transfer by community activists on the grassroots. 
information that is intended to be passed on needs to fall on fertile soil, otherwise the transfer process fails. Hence, both credibility and readiness are intertwined and interdependent if the transfer process is to be successful. Credibility of the activist is crucial but not sufficient on its own; readiness of the peers to listen does not lead to a functioning transfer process alone if the person who passes on information is not perceived as credible by the peer group. The model of transfer shows that the process requires both factors; the implications and interrelation of these two key factors are explained below.

\section{Credibility of the Activist}

The key factor "credibility of the activist" originates in the many personality traits that were mentioned by the interviewees as decisive for their ability to reach out to their peer groups. What appears to be particularly striking is the different perception of paramilitaries and how being affiliated with a paramilitary organization seems to induce or hamper credibility. In Northern Ireland, it was argued that peers tend to listen to those activists who themselves fought and suffered during the Troubles: "They speak the same language and that sounds like a cliché but they talk the talk and they walk the walk. They demonstrated that they were willing to pay the ultimate sacrifice" (Pa., personal communication, April 10, 2008). Mi. from a community organization in Derry emphasized the observation that people with a record of personal suffering in the name of the community can leverage this when it comes to transfer of positive insights and attitudes:

What gives people credibility on the other side is their own reputation within their own community. Now this works on two levels. People who are ex-paramilitary now working in their community have a lot of clout within their community. They are very effective in trying to prevent young people to go through what they have gone through (Mi., personal communication, April 17, 2008).

When it comes to Republican community in Northern Ireland, the interviewees assessed the role of former paramilitaries fairly positively. Elsewhere Mi. highlights the different attitudes toward former paramilitaries in the Catholic and the Protestant community respectively:

The Catholic community has accepted paramilitary prisoners. This is not saying that they are all accepted with open arms. But there is more acceptance of paramilitary people coming back and working with communities than there has been with the Protestant communities with their loyalist prisoners. They find it more difficult to re-integrate back into their community. There is a crazy mindset on all of this and that is, within the Protestant mindset, if you break the law you are a criminal. You shouldn't have been doing what you are doing, bla, bla. And therefore you become that outcast (Mi., personal communication, April 17, 2008).

Apparently, then, credibility with the constituencies makes the community activists appear trustworthy. Pa., a scholar in Northern Ireland, convincingly argued that people who engaged in the paramilitary organizations were willing to give 
up everything for the sake of the community. It seems understandable that constituencies then tend to follow the recommendations and opinions of those key leaders - they have seen it and they have been through it all. Hence, in Northern Ireland, and especially in the Republican community, when a community activist was involved in a paramilitary organization, this activity can make him highly trustworthy and credible. This observation might be - to some extent - linked to findings on the role and perception of Palestinian suicide bombers in the Palestinian public opinion (Mishal and Sela 2000). Moghadam (2003), for example, argues that suicide bombing elevates the perpetrator's status once the attack was carried out. The social status of the suicide bomber's family increases as well. Taarnby (2003) takes a similar stance when he claims that following the terrorist logic, dying as a martyr places him above anybody else in the community, i.e. raising his social status.

This is not to say that a community activist, by any means, needs to have a paramilitary background to be credible. Indeed, many interviewees were never involved in a paramilitary grouping but are committed to their communities in the long-term. These community activists might have supported community development through peaceful means. Mi. from Derry is a very good example of this. In the late 1960s he was the victim of an IRA bomb attack in his then workplace. This certainly traumatic experience triggered his willingness to prevent individuals in the communities from killing each other, and he sought professional training to become actively involved in the community sector:

I think from my own record and my own reputation, I have a certain amount of credibility but not with everybody. There are some people that want my name not even to be mentioned in the room or tell people that they are working with that guy or whatever because people have their own agendas. For me, I'm a straight talker, say it as it is but I'm also someone who can be trusted (Mi., personal communication, April 17, 2008).

Similarly, Je., a Protestant community worker who has been engaged in the field for 35 years states:

\footnotetext{
But now I must say a lot of years now I've got tremendous support from this community and from the Catholic community as well. So, what I think is that they see where you are coming from. They see that you are not doing it for yourself but that you are genuinely promoting the area to support the young people and also to support the whole community (Je., personal communication, April 7, 2008).
}

Unlike in the interviews in Northern Ireland, former paramilitaries from the Kosovo Liberation Army (KLA), and more precisely the potential they might have, were not mentioned by any of the interviewees in Kosovo. Rather, the interviewees seemed to stress that it is their clean personal record that helps them to pass on the idea of cooperation that they have gained through their engagement in intercommunity dialogue. As one of the Albanian interviewees from R. stated: 
"They know that I'm sincere and that I never cheated on them" (Is., personal communication, September 22, 2008). Another Albanian interviewee who works for a large international organization in Pristina describes it similarly:

I don't know, there are many, many reasons why somebody would listen to you, whether you have a clear dossier behind you, whether you will are really clearly known within your community as a righteous one, or because you're doing something good, or you have managed something for different reasons. For me it was easy to reach any community because I have no files, no records, nobody remembers me as somebody taking sides (Bu., personal communication, September 29, 2008).

Even though it was not explicitly stated by the Kosovo interviewees, it might be the case that former paramilitaries, or indeed anybody who has been involved in violent (para-) military activities during the war, is stigmatized. It seems possible that war activities and combat operations - albeit for the 'cause' of the Albanian community - do not necessarily lead to social ingroup prestige. Indeed, as one of the private conversations with a regional coordinator of a small international NGO showed, many people joined the KLA for material benefits and not out of ideological reasons. Today, therefore, the communities do not see former paramilitaries as heroes who were willing to sacrifice for the good of the larger group. Rather, they perceive them as criminals who tried to profit from the war. Furthermore, the KLA lost out tremendously in the eyes of the people due to their actions in the post-war period. During this time, they acted as henchmen for those who paid them, and intimidating and killing indiscriminately. Moreover, they looted Serbian property and 'sold' it, and anybody trying to impede them was threatened, beaten, or even tortured. The fact that the interviewees did not refer to soldiers and paramilitaries as their identity group provides an insight into the facets of a successful agent of transfer in the case of Kosovo.

It was remarkable that Northern Irish community activists tended to be more self-aware than their counterparts in Kosovo. This observation can be explained in the following way: it might be that the interviewees in Northern Ireland are formed or affected by a more individualistic culture, in which the individual and the role of the individual in society is more dominant than the collective. In Kosovo, on the other hand, the interviews might be influenced by a collectivist culture, in which the individual submits his will under the will and norm of the collective (Paez, Martinez-Taboado, Arrosspide, Insua and Ayestaran 1998). Triandis $(1995,2000)$ confirms and elaborates that in collectivistic cultures; people prioritize ingroup goals over individual goals and form their behavior and actions according to ingroup norms instead of their own attitudes and convictions. This latter aspect has also been shown by Abrams, Ando, and Hinkle (1998), as well as Suh, Diener, Oishi, and Triandis (1998).

In a more individualistic society as Northern Ireland, the individual interviewee might assess himself as more influential and ascribe himself a fairly prominent role in the transfer process. In a collectivist society such as Kosovo (at least 
in comparison to Northern Ireland), the individual activist might not perceive his personal contribution as decisive; rather, it is the constitution of the peer group (ready to engage and to improve community relations), as well as other external aspects like the socio-economic situation, which affects the transfer process. This is not to say that interviewees in Kosovo neglect their personal role and the impact of their credibility entirely, it is just less prominently presented in the interviews. To challenge this explanation, one might argue that in collectivist societies the individual contribution of a person respected in the community could be significant. The data validates this assumption. Indeed, if a respected person, like the head of a family or an imam, tries to pass on certain messages, they should be fairly successful. The imam participating in this study confirmed that his position of authority within the Muslim community helps him to reach out to the people: It is his position of authority that makes him credible and trustworthy. Still, it is no contradiction to the finding that the interviewees in Kosovo tended to consider their personal contributions less central. Even if a person has a position of authority, his individual contribution might be limited if other aspects are more influential. In addition, a person holding a position of authority might continue to adhere to the norms of a collectivist culture: when asked about his personal role, he might be modest because he shies away from elevating himself over the collective. The finding that, obviously, not much esteem is given to former KLA members, does not come as a surprise when listening carefully to the interviews. At first glance, one might expect that in a collectivist culture such as Kosovo, combatants who seemingly fought for the community might enjoy a special status. However, what needs to be considered is that the actions of KLA members are highly disputed and seen as very critical as outlined earlier. Unlike IRA activists who can be admired for their commitment to the cause of the community, KLA members are perceived fairly negatively and selfishly. Rather than fighting for the cause of the community, the interviewees suggested that the KLA was fighting for their own benefit. Hence, they did not serve the community and consequently cannot expect being treated with respect.

What is more, interviewees in Northern Ireland might be more used to talking to foreign people about their personal roles in intercommunity relations. If they are more used to this, the interviewees might be more comfortable and selfconfident in analyzing their personal contribution to a phenomenon like transfer. It might also be the case that some interviewees in Northern Ireland emphasize their personal roles in order to stress how important it is to be from the area - to be someone who has experienced the conflict and suffered it in one way or the other. In a few conversations, some disdain resonated against people coming from outside and trying to fix things according to the book. This might be an additional explanation why some interviewees spoke eloquently about their personal role and how and why they believed their personal history has led to the credibility needed for the transfer process. 
As a first step in the theoretical placement, the discovery of credibility as a key factor in the transfer process allows connecting the findings to the existing theories on transfer from interactive conflict resolution and comparable meetings on the top/medium political level (for example, problem solving workshops). Kelman (1972, 2002), as well as Ropers (2004), suggest that participants of interactive conflict resolution or dialogue meetings should hold an influential position within and be well connected to society, especially with regard to downward transfer. The findings for the transfer process on a grassroots level indicate a similar direction. Even though the aspect here is named credibility, it resembles Kelman's and Roper's idea of having a central position and being influential and expands that idea at the same time. The findings conclude that a person needs to be credible to influence the transfer process and consequently his peers. In this regard, the findings can also be linked to social-psychological research on leadership and trust in leadership. Burke et al. (2007:611) found that "trust in leadership results in behavioral and attitudinal outcomes." They further argue that a high quality of leader-member exchange (LMX), as well as a good reputation of the leader, results in more trust. A low quality relationship between the leader and the members of his group, along with no prior relationship history between the two, leads to less trust (Burke et al. 2007:621). This research provides additional evidence for this observation and extends it. If the personal credibility of the community activist is high, constituencies tend to trust the recommendation of the activist more easily. Therefore, trust in the community activist occurs because of his personal history of community involvement.

This finding provides insights into credibility as an important aspect for successful transfer and provides concrete evidence of what accounts for credibility-a subject that was missing from previous studies on transfer. A person should have an influential position, but what exactly makes him influential? This research shows why credibility might be important and who would be a credible person to engage in an intercommunity project. This latter aspect might be of particular interest to practitioners, as it could provide important considerations in building cross-community encounters in different societies. The observations made on what makes for credibility and how this credibility allows community activists to reach out to their peers might as well be connectable to Max Weber's thoughts on the three origins of legitimacy: rational/ legal authority, charismatic authority, and traditional authority. Weber argues that authority can be legitimized through a system of rational rules and if authority is executed along these rules. It is these rules people obey, not the individual executing authority. Hence, it is not personal authority. Charismatic and traditional authority, again, are personal according to Weber. Here, authority derives from the charisma of the leader; the leader being a hero or a person with some supernatural capabilities. Personal authority can also originate in traditions or habits. People obey the traditional leader because it is common practice and habit to follow him. Particularly the latter two origins 
of authority, charisma and tradition, seem relevant to the results of this study. Charismatic authority, for example, appears to be relatable to community activists formerly affiliated with a paramilitary organization, such as a former IRA combatant. Serving the cause of the community with all means and not shying away from the danger of lethal consequences, former IRA members possess charismatic authority. They are, generally stated, perceived as heroes due to their actions and commitment. The concept of traditional authority strongly reminds of the status of the imam in the municipality of R. in Kosovo and how this position provides him with the necessary clout to reach out to his peers. As outlined earlier, the imam explicitly claimed that people in his community listen to him because he is the imam. It is this position that people traditionally respect and follow.

\section{Readiness of the Peer Group to Listen}

While credibility is undoubtedly important, a second key factor - readiness of the constituency to listen - is also center stage. In both cases, readiness is attributed to a couple of aspects that constitute/affect the readiness of the peer group to listen to the activist. The basic idea is that if the peer group is not ready to listen to any kind of positive message developed during intercommunity encounter, the community activists faces major challenges in reaching out to his peers. Hence, the transfer process is jeopardized if the peer group is not ready. The data offers a lot to the development of a model of transfer on the grassroots level. The factor readiness was deduced from several themes, which were mentioned in either one or both of the cases. Three major arguments were identified in the analysis of the interviews: community traits, the socio-economic situation in the community, and the influence of secondary parties. Community traits are composed of several sub-aspects, which adds complexity to the theme. For example, the degree of conflict related trauma among the peer group, its trustfulness, whether they vehemently claim to be ready for a change in intercommunity relations (as was mentioned repeatedly by Kosovar Albanian interviewees), being trapped in historical traditions, and whether the peer group seems to be tightly knit (potentially allowing the concept: if you win over one, you win many).

The socio-economic situation within the peer group on the micro level, and the wider community on the macro level, was strongly emphasized in both cases. This again is a very interesting finding as so far socio-economic aspects were not mentioned in the relevant transfer literature. The interviewees would speak about how high unemployment prevents people from thinking about issues of conflict resolution or community relation development. If economic concerns prevailed among the peer group, the interviewees were negative about the transfer process precisely because the readiness of their constituents to think about community relations was extremely limited. This positive correlation between the socio-economic 
situation in the communities and the willingness of the communities to listen appears understandable. In Northern Ireland for example, if people do not successfully pass high school, fail in the job market, and eventually become dependent on public benefits, they have other - seemingly more urgent - problems. Pa. from Derry states: "It is inevitable that you have sectarianism if you live in a scarce society, there is no hope for you and you can see the economy taking off but it doesn't affect you" (Pa, personal communication, April 10, 2008).

Here, the interviewee emphasizes that failure to include communities in the economic development of the region fuels existing conflicts. This notion is reflected in another interview with two interface workers from Belfast: "The problem that exists is, the areas where we live in and work in see no benefit. The working class areas in Belfast and the North of Ireland don't see any tangible benefits of the peace" (Se., personal communication, April 15, 2008).

Other interviewees confirm that economic development in the communities is desperately needed. Je. from a youth club in Derry argues:

But what we need, we need jobs. We need people to know that they will have a good quality of life, they wouldn't get a proper wage. (...) Industry jobs, that is what they should be concentrating on because you see when young people have good jobs and good money their lives will turn around because they take a pride in themselves, they take a pride in their homes. And in that sense it does good to their health, they feel more healthy, they feel more like socializing with other people because through their jobs they meet other Catholics. They are going to meet people from the Polish and from the Chinese or whatever, you know what I mean? And the whole world is going to change. But until that happens, apathy is going to remain and it is still here (Je., personal communication, April 7, 2008).

Another interviewee underlines the importance of the types of jobs that are needed for the region. In addition to the numerous part-time jobs, which do not cover the expenditures of the employees, the interviewee elaborates:

What they need to do is, you see, if they don't tackle the situation properly and create jobs, this must be our greatest investment. I give a chance to work... You see, tourism is mostly low-paid jobs. There are very few good paid jobs and an awful lot is part time and that is the reality here (Pe., personal communication, April 7, 2008).

Furthermore, jobs in the community sector may decline substantially as the funding of the European Union dries up by 2013. The lack of proper jobs in the area relates to other societal problems, such as substance misuse - particularly among adolescents and young adults:

We are stuck up there in the interface when we should really use the time and tackle the effects of alcohol on what happens in our society. If we are up in the interfaces when young boys attack each other, we should go into the off-licenses, into the bars to see if there are any young people there that shouldn't be in there... A lot of the problems in the North have now gone up and the people (actually) just want to live in peace. But a few drinks and they have their own interpretation of history and that's where the danger and problems come from (Pe., personal communication, April 7, 2008). 
It seems worth considering why transfer literature has neglected the negative impact of the socio-economic situation on information transfer. One explanation might be that transfer studies have predominantly focused on top- or medium political level meetings. On these societal levels again, especially on a top political level, socio-economic problems might not be as relevant and of concern as for people on the grassroots. This in turn is an important insight: apparently, when it comes to the grassroots level, transfer processes are heavily influenced by the socio-economic situation in the communities as this affects the readiness of the peer groups to listen to any positive information about the other conflict party.

When it comes to Kosovo, if there was a single idea to arise from the interviews, it would be the influence of Serbia on the Kosovar-Serbian population in the North of Kosovo and in the enclaves and how this influence impacts on the socio-economic situation in the country. Serbia has initiated a parallel structure in Kosovo - similar to the Kosovar Albanian structure before the war (Ukelli, 2008). This parallel structure in effect constitutes a state within the state of Kosovo. Kosovo Serbs have their own administration, schools, and health system, all of which are financed by Belgrade. Yannis (2003) alludes to the observation that, especially during the initial phase of UNMIK, the Serbian parallel structures provided more reliable services to their local people than did the international administration. This helped the extremists in Serbia and Kosovo to gain support for their stance: eventually they were more capable of helping their people than the international players.

The incentive Belgrade offers is compelling. The interviews indicated that Belgrade dictates, or at least heavily influences, the ingroup norms within the Serbian community: Kosovo is part of Serbia and any engagement in the official institutions of Kosovo implies the acceptance and legitimacy of these institutions. One Albanian interviewee from R. stated:

In the moment we achieved to engage the minorities into the institutional life then through the influence of Belgrade even though they didn't want to, they retrieved themselves from the institutional life (Ab., personal communication, September 23, 2008).

Another Albanian interviewee claimed that Belgrade assails the Serbian communities in Kosovo with propaganda:

Propaganda, political propaganda still disturbs the communication between Kosovar citizens. I'm not saying that this is not also on the Albanian side but on the Albanian side it is not institutional, it is private from different individuals on the Serbian side it is institutional from Belgrade and in the institutional way they request the citizens of Kosovo (Is., personal communication, September 22, 2008).

The influence of Serbia on the Serbian community in Kosovo differs. There are apparently those community members who feel strongly affiliated with Serbia and who cannot and/or do not want to become part of the state of Kosovo. It is 
not clear whether this group objects to Kosovo voluntarily, i.e. due to their personal convictions, or whether they become overwhelmingly affected by the sticks and carrots that Serbia applies to them. Most of the Albanian interviewees argue that the opposition of the Serbians is economically motivated, since they earn better money when working in the parallel structures. Some Albanian interviewees, such as Fl. from a regional NGO in Kosovo, emphasize that the Serbians are pressured to adhere to social ingroup norms. People who deviate from these ingroup norms can face severe repercussions from their own community. This appears to be the case for Bo., a Serb from R. who works for the municipality in $\mathrm{R}$. He seems to belong to the group of Serbians in Kosovo who see their future within this state. They try to integrate and become part of the structure. Bo. is apparently not challenged by his immediate constituency, like his family, but the wider community criticizes him for being engaged in the Kosovo institutions. It seems obvious that people like Bo. would need to be vehemently backed up by the Kosovo government. ${ }^{5}$ Indeed, this is a double-edged sword, as others might perceive this support as favoritism. Still, if Bo. is properly integrated and is able to get his message heard within the institutions, he can become a role model for other Serbians. Furthermore, it would show to other individuals that it is worth engaging in the official Kosovar structures. This might be an incentive for Serbians to turn away from the parallel structures provided by Serbia. Albanian interviewees perceive Serbia's engagement in Kosovo as highly detrimental. Serbia supports a parallel structure for and within the Serbian community. The financial incentives provided by the parallel structures are appealing, particularly against the background of the tense economic situation in Kosovo and the lack of integration and participation of the Serbian community in Kosovo's economy.

The impact of the readiness of the constituencies to listen to messages that come from dialogue encounters on the transfer process has only been analyzed to a minor degree in the relevant literature. This holds particularly true when it comes to the assessment of socio-economic aspects by the interviewees and how these aspects interfere with the transfer process. Some ideas about tension on the ground have been provided so far - for example Chataway, Kelman (1997) or Rouhana (2000) - however, no study on transfer has provided a comprehensive list of factors or investigated in detail why certain conditions might affect the readiness of the peer groups to listen. This research provides insights into what might facilitate the tension and hostility between the communities, namely community traits, (trauma, 'being stuck' in historical traditions), socio-economic conditions, as well as the influence of secondary parties. In contrast to conflict

\footnotetext{
5) Sasa Rasic, the Minister for Community and Return of the Kosovo government, is a prominent role model. He succeeded Slavisa Petkovic who was the leader of the Serb Civic Initiative and became minister in January 2005 (Tütsch 2005). Hence, Kosovo Serbs such as Bo. who try to integrate into the Kosovo society can refer to well-known cases of Serbian integration into the political affairs of Kosovo.
} 
resolution research, numerous social-psychological studies have stressed that people with strong ingroup identification are particularly eager to save their group from the threats and attacks of an outgroup, i.e. the opposing conflict party (Coser 1956; Sherif, Harvey, White, Hodd and Sherif 1961; Sherif 1966; Duckitt 2001; Stephan and Stephan 2000; Bobo 1983, Doty, Peterson and Winter 1991; Duckitt and Fisher 2003; Esses, Jackson and Armstrong 1998; Esses, Dovidio, Jackson and Armstrong 2001; Stephan et al. 2002; McLaren 2003). Positive news about the other conflict party might be perceived as a threat. The following quotes from Northern Ireland serve as an example of the challenges posed by historical traditions: if people in the communities are caught in their beliefs and in history, it makes it difficult to reach out to them. They are just not ready, as these two exemplary statements highlight:

\begin{abstract}
1. (...) some people are so entrenched in their beliefs about other people that they are not open to listening. There are people who do not actually hear because they are so entrenched. They believe so much that what they know is the truth about the other person. (...) But there are people who are not... and it doesn't suit them to be receptive. They want to hold on to what they are, who they are, and to keep all of that. So it is not really [expression not understandable, author's note] ... they are not open to hear that some things might get different because, from their perspective or where they are at, it doesn't suit (An., personal communication, April 21, 2008).

2. Every time you do that, it is against the knowledge of history and against the knowledge of their learned experience. And if they hadn't have a practical experience with a member of the other community, all of their...and which is the other community are from history, are from narrative, are from experiences that are handed down rather than coming out from behind the barrier to take a look at the other side of the fence. (...) But as long as we are stuck behind the walls and barriers of 400 , or 600 , or 800 years of history we haven't got a future. You know, history shouldn't be our benchmark. It shouldn't be where everything gets stuck (Jo., personal communication, April 7, 2008).
\end{abstract}

Thus, the interviews seem to strengthen the argument that those who identify strongly with their group reject anything that is not in line with their interpretation of history. This again implies that people whose ingroup identification is strong are less ready to listen to the idea of cooperation with the opposing conflict party.

When it comes to the transfer process on a grassroots level, the research offers more substantive insights into how the situation of and within the peer group affects the process of passing on certain messages. It became clear that "readiness of the peer group" describes a complex interplay of the various aspects better than a factor named 'tension on the ground.' While tension on the ground can affect the readiness of the peer group, and through that hamper the transfer process, it is more than just tension evoked by violent clashes that impacts readiness. This article has demonstrated how other aspects, like trauma or the economic situation, shape readiness. These findings are a major asset of the study because they comprehensively elaborate the crucial factors of the transfer process.

Most importantly, the results blend in very well with findings on processes of social influence. The model postulated here confirms insights from social influence 
literature and elaborates them at the same time at a tangible political level. It seems obvious that the transfer model is a model of social influence. As suggested by Kelman (1958), Clark and Maass, or French and Raven, credibility of the sender of the information is vital for social influence. The interviews highlighted exactly this aspect: community activists believe that they can affect their peer groups or are heard by their peers, if they, the community activists, are sufficiently credible, trustworthy, or in a position of authority like the imam in Kosovo. As outlined earlier in reference to Max Weber, the imam exerts legitimate power in French and Raven's terms and affects people in his community by these means.

The present study verified another essential aspect of social influence suggested by Moscovici et al. and Nemeth et al. Going back to what interviewee Je. from Derry said about her life-long dedication to cross-community relationship development, that a minority needs to be firm and convinced in its opinion if they want to affect the majority. Je. or An. might not have been actively involved in the violent resistance and did not gain credibility through that. Still, they have promoted an inclusive and integrated Northern Irish society for decades, despite the challenges they had to face. It seems legitimate to assume that these interviewees affect their peers because of their stable commitment to their personal conviction. This research extends the findings on social influence to actual conflict resolution tools and processes namely transfer from intercommunity encounters. The analysis of the interviews in Northern Ireland and Kosovo shows that the mechanisms of social influence are certainly not constrained to experimental settings. This study did not only confirm the importance of source credibility as put forward in social influence literature, but also stressed the impact of the recipient's motivation to be influenced. Particularly this latter aspect - the recipient's motivation - is a factor that has been long promoted in social influence literature but that has received only minor attention in conflict resolution transfer studies. This research confirms the enormous significance of the recipient's motivation as proposed in social influence studies and recommends putting it center stage for understanding transfer processes.

Social influence scholars like Petty, Cacioppo, and Goldman or Deutsch and Gerard pointed out that recipients of influence/information need to be motivated to process that information. Otherwise, the social influence process fails. The present study validates these thoughts excellently. If the peer groups of the community activists are not ready for various reasons, i.e. not motivated to listen to ideas passed on to them by their community activist, the transfer process falls short. The interviewees particularly emphasized external aspects that affect the motivation of the peer groups to listen to their messages. The socio-economic situation in the communities was key in this regard and cannot be overestimated for its effect on recipients' motivations to process information. The dominance of the socio-economic situation in the interviews underlines again that the conditions in the communities need to have top priority in peacebuilding processes. 
It is social influence literature that teaches us how and why this is vital to consider: if peers are to change their attitudes, they need to be motivated to process information.

\section{Conclusion}

How do community activists construe the transfer process from intercommunity encounters? The transfer process on the grassroots level is affected by the credibility of the activist, as well as by the readiness of the community to listen to the activist. Credibility emerges through the actions and attitudes of the activist (for example, a history of suffering for the community and devotion to the community). Readiness is affected by different elements, which either refer to community traits (for example, traumatized or willing to engage), the socio-economic situation, or external parties such as Serbia. The transfer process seems particularly dependent on the readiness of the peer group because the peer group needs to be motivated to process information. A community activist might be highly credible, but if the economic situation is too tense, the peer group might just not be ready to listen to him. Hence, the messages of a community activist about cooperation with the other side for example can affect his peer group, nevertheless he is dependent on the conditions among his peers and in the wider community. Still, even if the community activist does not reach out to his peers right away and change their perception about the other conflict party, he can add to changing the tones about the other side and the relationship with the other side. If the community activist voices his positive perception about the other, it gives raise to another image and discourse within his community. This again might not alter the public opinion immediately but having it out there and presented by a respected figure of the community can induce change in the long-run.

What is more, the transfer model integrates very well to already existing findings on social influence. The model confirms substantial aspects of social influence processes discovered in social-psychological research, such as the massive impact of source credibility on the side of the influencer or sender of the information and the motivation of those to be influenced to process information passed on to them. This research adds to the social influence literature with a highly practical and politically relevant example. It also strongly suggests considering information transfer from intercommunity encounters as part of the wider field of social influence.

The findings of this study suggest a number of policy recommendations. Policy makers and donor agencies should be looking for community activists who have sufficient credibility among their peers. It seems advisable to conduct prior investigations within the target area and community in order to identify adequate actors. Even if prior investigations may be time-consuming and possibly costly at 
the beginning, it is anticipated that this initial effort will eventually pay off substantially. The 'right' ones, that is, most credible people within a community, will be much more successful at passing on messages from intercommunity meetings. The results from this research indicate who might be credible: a former paramilitary, someone engaged extensively in the development of his community, someone who has devoted himself to the community by helping out the weak, or someone with authority, such as a local religious leader (if religion matters to the people in the community). With regard to former paramilitaries or other former combatants, policy makers need to take into account the standing of the respective groupings within the community. The community might highly respect those who fought, or the community might despise them. To be sensitive to the particular context is, therefore, indispensable for practitioners. Practitioners are required to know the perspective of the wider community on controversial figures such as paramilitaries.

Close cooperation with local organizations cannot be overestimated, especially for foreign donor agencies. As highlighted in this article, local ownership of peace processes of any kind is essential. Local organizations usually have resources and knowledge, which international organizations working in the field may lack. Locals can recommend funding of people or groups that might have already formed. The normal person on the ground tends to trust a local organization more than an international one. Therefore, local organizations can better reach out to the people because they talk the talk and walk the walk - a quality which internationals occasionally lack. Yannis (2003) outlines that "one should not overestimate the policing capabilities of the international community in a foreign terrain in which the population has a long and sophisticated tradition of clandestine activities and a widespread gun culture" (183). Yannis' observation confirms that it indispensable - particularly for Western peacebuilding/civil society activists - to thoroughly assess the realities on the ground before implementing any sort of policy. In addition, international agencies should take notice that their money supports the peace process and not Western advisers and NGOs, as criticized by Veremis (2005).

Nepotism might challenge the cooperation between international donor agencies and the local organization, especially when local organizations promote particular people who benefit them personally rather than have professional relevance. If international donors establish a trustful and possibly personal relationship with the local organization, this might be avoided. The international donor would then not seem to be an abstract partner, there just to provide money, but rather the donor might be perceived as a partner that the local organization does not wish to betray.

Practitioners and donor agencies can choose whom to work with and at whom to direct their resources. However, it is considerably more difficult, to affect the readiness of a community to listen to ideas derived from intercommunity initiatives. 
The results highlight the complex interaction between the various aspects that affect the readiness of a community. A single donor agency can certainly not address the socio-economic challenges within a community because it is up to governments, international organizations, and enterprises to improve this situation. Governments need to provide a framework that allows the business sector to flourish. International organizations or foreign governments might need to financially support a conflict-ridden area, and enterprises need to be willing to invest in the area and employ local people. Moreover, if a community is still severely traumatized, there should ideally be mechanisms and processes that help the traumatized to come to terms with the past. Again, individual donors or practitioners might not have the means to provide these services. It is also recommended that practitioners try to cooperate with other practitioners. Specialized practitioners might engage in trauma related work and through that advance the readiness of the community. Practitioners may also lobby governments to develop programs that improve the socio-economic situation within the communities. Here, it might be advisable to inform large lobby groups about the situation in the communities so that these groups can use this knowledge in their campaigns. Hence, with regard to readiness, practitioners are strongly advised to look for cooperation with other players. What seems most promising is to combine efforts.

\section{References}

Abrams, D., Ando, K., and Hinkle, S. (1998). "Psychological Attachment to the Group: CrossCultural Differences in Organizational Identification and Subjective Norms as Predictors of Workers' Turnover Intentions.” Personality and Social Psychology Bulletin 24,10: 1027-1039.

Belloni, R. (2001). "Civil Society in Peacebuilding in Bosnia and Herzegovina." Journal of Peace Research 38,2: 163-180.

Birrell, D., and Williamson, A. (2001). "The voluntary-community sector and political development in Northern Ireland since 1972." Voluntas: International Journal of Voluntary and Nonprofit Organizations 12,3: 205-220.

Bobo, L. (1983). “White's opposition to busing: Symbolic racism or realistic group conflict?” Journal of Personality and Social Psychology 45: 1196-1210.

Burke, C. S., Sims, D. E., Lazzara, E. H., and Salas, E. (2007). “Trust in leadership: A multi-level review and integration." The Leadership Quarterly 18: 606-632.

Cacioppo, J. T., \& Petty, R. E. (1982). "The need for cognition." Journal of Personality and Social Psychology 42: 116-131.

Cartwright, D., and Zander, A. (1968). "Power and Influence in Groups: Introduction," in D. Cartwright and A. Zander editors, Group Dynamics. New York: Harper \& Row Publishers (3rd ed., pp. 215-235).

Chataway, C. J. (2002). “The Problem of Transfer from Confidential Interactive Problem-Solving: What Is the Role of the Facilitator?” Political Psychology, 23,1: 165-189.

Cialdini, R. B. (1984). Einfluss: wie und warum sich Menschen überzeugen lassen (W. Riehl, Trans.). Landsberg am Lech: Moderne Verlags-Gesellschaft.

Clark, R. D., \& Maass, A. (1988). "The role of social categorization and perceived source credibility in minority influence." European Journal of Social Psychology 18: 381-394. 
Coser, L. A. (1956). The functions of social conflict. Glencoe, IL: Free Press.

Cox, M. (1998). "'Cinderella at the Ball': Explaining the End of the War in Northern Ireland." Millennium - Journal of International Studies 27, 2: 325-342.

Cuhadar, C. E. (2009). "Assessing Transfer from Track Two Diplomacy: The Case of Water and Jerusalem." Journal of Peace Research 46, 5: 641-658.

Curran, D. and Sebenius, J. K. (2003). "The Mediator as Coalition Builder: George Mitchell in Northern Ireland.” International Negotiation 8, 1: 111-147.

— Northern Ireland with Richard Holbrooke in Bosnia-Herzegovina." Negotiation Journal 20, 4: 513-537.

De Chastelain, J. (2003). "The Good Friday Agreement in Northern Ireland," in C. Crocker, Chester, F. O. Hampson and P. Aall editors, Herding Cats. Multiparty Negotiations in a Complex World. Washington D.C.: United States Institute of Peace Press.

Deutsch, M., and Gerard, H. B. (1955). "A study of normative and informational influence on individual judgment." Journal of Abnormal and Social Psychology 51: 629-636.

Dixon, P. (2001). Northern Ireland: The Politics of War and Peace. New York: Palgrave.

- (2002). "Northern Ireland and the International Dimension: The End of the Cold War, the USA and European Integration." Irish Studies in International Affairs 13: 105-120.

Doty, R. M., Peterson, B. E., and Winter, D. G. (1991). "Threat and authoritarianism in the United States, 1978-1987." Journal of Personality and Social Psychology 61: 629-640.

Duckitt, J. (2001). "A dual process cognitive-motivational theory of ideology and prejudice." Advances in Experimental Social Psychology 33: 41-113.

Esses, V. M., Dovidio, J. F., Jackson, L. M., and Armstrong, T. L. (2001). "The Immigration Dilemma: The Role of Perceived Group Competition, Ethnic Prejudice, and National Identity." Journal of Social Issues 57, 3: 389-412.

—, Jackson, L. M., and Armstrong, T. L. (1998). "Intergroup Competition and Attitudes Towards Immigrants and Immigration: An Instrumental Model of Group Conflict." Journal of Social Issues 54, 4: 699-724.

Fisher, R. J. (1997). Interactive Conflict Resolution. Syracuse, NY: Syracuse University Press.

(2005). Paving the way - Contributions of interactive conflict resolution to peacemaking. Lanham, MD: Lexington Books.

(2009). "Interactive Conflict Resolution. Dialogue, conflict analysis, and problemsolving" in D. J. D. Sandole, S. Byrne, I. Sandole-Staroste and J. Senehi editors, Handbook of Conflict Analysis and Resolution. New York, NY: Routledge, 328-338.

French, J. R. P., and Raven, B. (1968). "The Bases of Social Power," in D. Cartwright and A. Zander editors, Group Dynamics. New York: Harper and Row, 259-269.

Heatley, C. (2004). Interface: Flashpoints in Northern Ireland. Belfast: Lagan Books.

Kaufman, E. (2002). "Sharing the Experience of Citizens' Diplomacy with Partners in Conflict," in J. Davies and E. Kaufman editors, Second Track/Citizen Diplomacy: Concepts and Techniques for Conflict Transformation. Lanham: Rowman and Littlefield Publishers, 183-212.

Kelman, H. C. (1958). "Compliance, Identification, and Internalization. Three Processes of Attitude Change." Journal of Conflict Resolution 2, 1: 51-60.

—. (1997a). "Group Processes in the Resolution of International Conflicts: Experiences from the Israeli-Palestinian Case." American Psychologist 52, 2: 212-220.

(1997b). "Nationalism, patriotism, and national identity: social-psychological dimensions," in D. Bar-Tal and E. Staub editors, Patriotism in the Lives of Individuals and Nations. Chicago: Nelson-Hall,165-189.

- (1997c). "Social-Psychological Dimensions of International Conflict," in I. W. Zartman and J. L. Rasmussen editors, Peacemaking in International Conflicts: Methods and Techniques. Washington, D.C.: United States Institute of Peace. 
(1998). "Interactive Problem Solving: An Approach to Conflict Resolution and Its Application in the Middle East." PS: Political Science \& Politics 31, 2): 190-198.

(2000). "Building Trust Among Enemies: The Central Challenge to Peacemaking Efforts," in W. Krieg, K. Galler and P. Stadelman editors, Richtiges und Gutes Management: Vom System zur Praxis. Festschrift für Fredmund Malik. Bern: Haupt.

_ (2005). "Building trust among enemies: The central challenge for international conflict resolution." International Journal of Intercultural Relations 29, 6: 639-650.

Kuperman, A. J. (2008). "The Moral Hazard of Humanitarian Intervention: Lessons from the Balkans." International Studies Quarterly 52, 1: 49-80.

Kurki, M. (2008). Causation in International Relations. Reclaiming Causal Analysis. Cambridge: Cambridge University Press.

Lantschner, E. (2008). "Protection of Minority Communities in Kosovo: Legally Ahead of European Standards - Practically Still a Long Way to Go." Review of Central and East European Law 33: 451-490.

Lederach, J. P. (1997). Building peace: sustainable peace in divided societies. Washington, D.C.: United States Institute of Peace.

Lepgold, J., and Nincic, M. (2001). Beyond the Ivory Tower: IR Theory and the Issue of Policy Relevance. New York: Columbia University Press.

Martin, R., and Hewstone, M. (2003). "Majority versus minority influence: When, not whether, source status instigates heuristic or systematic processing." European Journal of Social Psychology 33: 313-330.

McLaren, L. (2003). "Anti-Immigrant Prejudice in Europe: Contact, Threat Perception, and Preferences for the Exclusion of Migrants." Social Forces 81, 3: 909-936.

Mitchell, C. R. (1981). Peacemaking and the consultant's role. Westmead, UK: Gower.

- (1993). "Problem-solving exercises and theories of conflict resolution," in D. Sandole and H. v. d. Merwe editors, Conflict resolution theory and practice - integration and application. Manchester, UK: Manchester University Press.

Mishal, S. \& Sela, A. The Palestinian Hamas. Vision, Violence, and Coexistence. New York: Columbia University Press.

Moghadam, A. (2003). "Palestinian Suicide Terrorism in the Second Intifada: Motivation and Organizational Aspects." Studies in Conflict \& Terrorism 26: 65-92.

Moscovici, S., Lage, E., and Naffrechoux, M. (1969). "Influence of a consistent minority on the responses of a majority in a color perception task.” Sociometry 32: 365-380.

— behavior in a perceptional task." Journal of Experimental Social Psychology 16: 270-282.

Mugny, G., and Perez, J. (1991). The social psychology of minority influence. Cambridge, UK: Cambridge University Press.

Nemeth, C., Swedlund, M., and Kanki, B. (1974). "Patterning of the minority's response and their influence on the majority." European Journal of Social Psychology 4:53-64).

Paez, D., Martinez-Taboado, C., Arrospide, J. J., Insua, P., and Ayestaran, S. (1998). "Constructing Social Identity: The Role of Status, Collective Values, Collective Self-Esteem, Perception and Social Behaviour," in S. Worchel, J. F. Morales, D. Paez and J.-C. Deschamps editors, Social Identity. International Perspectives. London: Sage Publications, 211-229.

Peck, C. (1998). Sustainable Peace: The Role of the UN and Regional Organizations in Preventing Conflict. London: Rowman \& Littlefield.

Petty, R. E., Cacioppo, J. T., and Goldman, R. (1981). "Personal involvement as a determinant of argument-based persuasion.” Journal of Personality and Social Psychology 41: 847-855.

Pouligny, B. (2005). "Civil Society and Post-Conflict Peacebuilding: Ambiguities of International Programmes Aimed at Building 'New' Societies.” Security Dialogue 36, 4: 495-510. 
Ropers, N. (1995). Peaceful Intervention: Structures, Processes, and Strategies for the Constructive Regulation of Ethnopolitical Conflict. Berlin: Berghof Forschungszentrum für konstruktive Konfliktbearbeitung.

(2004). From resolution to transformation: The role of dialogue projects. Berlin: Berghof Forschungszentrum für konstruktive Konfliktbearbeitung.

Rouhana, N. (2000). "Interactive Conflict Resolution: Issues in Theory, Methodology and Evaluation," in P. C. Stern and D. Druckman editors, International Conflict Resolution After The Cold War. Washingtion, D.C.: National Academy Press, 294-335.

Sherif, M. (1966). Group conflict and cooperation: Their social psychology. London: Routledge and Kegan Paul.

—, Harvey, O. J., White, J., Hodd, W., and Sherif, C. W. (1961). Intergroup conflict and cooperation: The robbers cave experiment. Norman, OK: University Book Exchange.

Statistical Office of Kosovo (2008). Demographic changes of the population of Kosovo 1948-2006 Retrieved 12 March 2009. from www.ks-gov.net.

Stephan, W. G., Boniecki, K. C., Ybarra, O., Bettencourt, A., Ervin, K. S., Jackson, L. A., et al., (2002). "The role of threats in the racial attitudes of Blacks and Whites." Personality and Social Psychology Bulletin 28, 9: 1242-1254.

— Reducing prejudice and discrimination. Hillsdale, NJ: Erlbaum.

Stevenson, J. (1998). "Peace in Northern Ireland: Why Now?” Foreign Policy 112: 41-54.

Suh, E., Diener, E., Oishi, S., and Triandis, H. C. (1998). "The shifting basis of life satisfaction judgements across cultures: Emotions versus norms." Journal of Personality and Social Psychology 74, 2: 482-493.

Tütsch, C. (2005). Kosovo's Burdensome Path to Economic Development and Interethnic Coexistence. Bern: Swiss Peace Foundation.

Turner, J. C. (1991). Social influence. Buckingham: Open University Press.

—, Wetherell, M. S., and Hogg, M. A. (1989). "Referent informational influence and group polarization.” British Journal of Social Psychology 28: 135-147.

Triandis, H. C. (1995). Individualism and Collectivism. Boulder, CO: Westview Press.

- (2000). "Culture and Conflict." International Journal of Psychology 35, 2: 145-152.

Ukelli, S. (2006). Ist der Frieden im Kosovo/Kosova von Dauer? Herausforderungen der kosovarischen Gesellschaft im Transformationsprozess unter besonderer Berücksichtigung der Politik und Wirtschaft: Eine Bestandsaufnahme (Vol. 114). Linz: Trauner Verlag.

Veremis, T. (2005). Western Amateurs in the Balkans and the End of History. BALCANICA, XXXVI, 237-246.

Weber, M. Wirtschaft und Gesellschaft. Paderborn: Voltmedia.

Yannis, A. (2001). ”Kosovo Under International Administration.” Survival, 43(2), 31-48.

- (2003). "Kosovo: The Political Economy of Conflict and Peacebuilding," in K. Ballentine and J. Sherman editors, The Political Economy of Armed Conflict. Beyond Greed \& Grievance. Boulder, CO: Lynne Rienner Publishers Inc. 167-195. 